\title{
New insights about the introduction of the Portuguese oyster, Crassostrea angulata, into the North East Atlantic from Asia based on a highly polymorphic mitochondrial region
}

\author{
Ana Grade ${ }^{1,2}$, Hicham Chairi ${ }^{3}$, Delphine LALlias ${ }^{4,5}$, Deborah M. Power ${ }^{6}$, Francisco RUANO ${ }^{2}$, \\ Alexandra LEITÃO ${ }^{1,7}$, Teresa DRAGO ${ }^{1,8}$, Jonathan W. $\mathrm{KING}^{4}$, Pierre BoUdRY ${ }^{9}$ \\ and Frederico M. BATISTA ${ }^{1,6, a}$ \\ 1 Instituto Português do Mar e da Atmosfera, Estação Experimental de Moluscicultura de Tavira, Av. 5 de Outubro, 8700-305 Olhão, Portugal \\ ${ }^{2}$ Instituto Português do Mar e da Atmosfera, Av. de Brasília, 1449-006 Lisboa, Portugal \\ 3 Université Abdelmalek Essaâdi, Faculté Polydisciplinaire de Larache, Département de Biologie, B.P. 745, 92004 Larache, Morocco \\ ${ }^{4}$ Centre for Applied Marine Sciences, School of Ocean Sciences, College of Natural Sciences, Bangor University, Menai Bridge, Anglesey \\ LL59 5AB, UK \\ 5 Current address: GABI, INRA, AgroParisTech, Université Paris-Saclay, 78350 Jouy-en-Josas, France \\ 6 Centro de Ciências do Mar (CCMAR), Universidade do Algarve, Campus de Gambelas, 8005-139 Faro, Portugal \\ 7 Environmental Science Center (ESC), Qatar University, P.O. Box: 2713 Doha, Qatar \\ 8 Instituto Dom Luiz, Faculdade de Ciências da Universidade de Lisboa, Campo Grande, Edifício C1, Piso, 1749-016 Lisboa, Portugal \\ 9 Ifremer, Unité de recherche Physiologie Fonctionnelle des Organismes Marins, Laboratoire des Sciences de l'Environnement Marin (UMR \\ 6539 LEMAR CNRS/UBO/IRD/Ifremer), ZI de la Pointe du Diable, CS 10070, 29280 Plouzané, France
}

Received 12 July 2016; Accepted 2 December 2016

\begin{abstract}
It is commonly presumed that the Portuguese oyster Crassostrea angulata was introduced into the North East (NE) Atlantic from Asia. The analysis of the nucleotide sequence of a highly polymorphic non-coding mitochondrial region (major noncoding region - MNR) of C. angulata samples collected in Europe (Portugal), Africa (Morocco) and Asia (Shantou and Taiwan) provided new insight into the introduction of this species into the NE Atlantic. Sixty haplotypes and a nucleotide diversity of 0.0077 were observed in 130 analyzed sequences. Higher nucleotide diversity levels were observed in NE Atlantic sites than in Asian sites and significant genetic differentiation was found between the two. Our results suggest that $C$. angulata might have been introduced to the NE Atlantic by multiple introductory events, though the exact origins remain unknown since none of the analyzed Asian sites seemed to have been a source of introduction. The nucleotide diversity of $C$. angulata was higher than that previously reported for Pacific oyster $C$. gigas in Europe and Asia for the same mitochondrial region. The results obtained in the present study suggest that NE Atlantic $C$. angulata stocks are a unique genetic resource, which highlights the importance of their conservation.
\end{abstract}

Keywords: Crassostrea angulata / phylogeography / genetic signature / biological invasions

\section{Introduction}

The Portuguese explorer Vasco da Gama (ca. 1460-1524) was the first European to reach India by sea in 1498 by sailing around the Cape of Good Hope and across the Indian Ocean. In 1511, the contest of Malaca led by the Portuguese general Afonso de Albuquerque was of crucial importance for the establishment of a commercial maritime route between Europe and Asia (India and China) (Boxer 1969). As many marine organisms can survive attached to the hull of vessels it is possible that Asian species may have been introduced via this route as

a Corresponding author: fmbatista@yahoo.com early as the XVI century, but this has remained poorly documented until recently (Seebens et al. 2013).

Biological invasions can have dramatic ecological and economic impacts (Simberloff et al. 2013). However, some species introduced involuntary or voluntary have a high social and/or economic importance, which is notably the case in Europe for several marine bivalve species such as the Pacific oyster Crassostrea gigas (Thunberg, 1793) and the Manila clam Ruditapes philippinarum (Adams and Reeve, 1850).

C. gigas was originally described in Asia whereas the Portuguese oyster $C$. angulata (Lamarck, 1819) was first described in the NE Atlantic. Several comparative studies based on larval shell morphology (Ranson 1960) and allozyme 
Table 1. Genetic diversity of $C$. angulata samples estimated from comparisons of sequences of the major noncoding region (position 1061711217 bp of EU672832) of mitochondrial DNA.

\begin{tabular}{ccccccc}
\hline Site & $n$ & $S$ & $h$ & $k$ & Hd (SD) & $\pi(\mathrm{SD})$ \\
\hline Sado (Portugal) & 26 & 22 & 14 & 5.09 & $0.929(0.028)$ & $0.00760(0.00068)$ \\
Mira (Portugal) & 28 & 22 & 17 & 5.20 & $0.960(0.018)$ & $0.00791(0.00064)$ \\
Tahaddart (Morocco) & 21 & 24 & 13 & 4.63 & $0.862(0.073)$ & $0.00705(0.00103)$ \\
Shantou (China) & 27 & 27 & 11 & 3.90 & $0.832(0.052)$ & $0.00594(0.00091)$ \\
Keelung (Taiwan) & 28 & 36 & 22 & 3.83 & $0.958(0.030)$ & $0.00583(0.00058)$ \\
Total & 130 & 64 & 60 & 5.07 & $0.968(0.007)$ & $0.00770(0.00036)$ \\
\hline
\end{tabular}

$n$, number of individuals analyzed; $S$, number of variable sites; $h$, number of haplotypes; $k$, mean number of nucleotide differences; Hd, haplotype diversity (standard deviation); $\pi$, nucleotide diversity (standard deviation).

markers (Mathers et al. 1974; Buroker et al. 1979) suggested that the two taxa were the same species. Studies using other types of genetic markers also reached a similar conclusion (López-Flores et al. 2004; Cross et al. 2006). Several studies have reported the production of F1 hybrids between $C$. angulata and C. gigas under experimental conditions (Imai and Sakai 1961; Menzel 1974; Huvet et al. 2002; Batista et al. 2007). Hybrids between $C$. angulata and $C$. gigas have also been reported in the wild (Huvet et al. 2004) and first generation hybrids were shown to be fully viable and fertile under experimental conditions (Huvet et al. 2002). However, several phenotypic and genetic differences were also reported between $C$. angulata and C. gigas (for review see Batista et al. 2009). Based on the sequence of the mitochondrial genome the two species were estimated to have diverged about 2.7 million years ago (Ren et al. 2010). The close relationship between $C$. angulata and C. gigas has led several authors to suggest that they have a recent common origin (e.g. Ranson 1960). Phylogenetic analysis by O'Foighil et al. (1998) suggested that C. angulata has been recently introduced to Europe from Asia. Moreover, Boudry et al. (1998) based on PCR-RFLP data were the first to report the presence of $C$. angulata in Taiwan. Since then, several studies have reported the presence of $C$. angulata in Asia, namely in China (Làpegue et al. 2004; Xia et al. 2009; Wang et al. 2010) and more recently in Okinawa Island, Japan (Sekino and Yamashita 2013).

The absence of Crassostrea sp. shells in shell middens in Europe, contrasts with the abundance of shells from the European flat oyster Ostrea edulis (e.g. Gutiérrez-Zugasti et al. 2011; Drago et al. unpublished data) and is an additional argument in support of the hypothesis that $C$. angulata was introduced from Asia into Europe, rather than being part of its natural range. Shell middens in Portugal (southern Portugal and Tagus River valley) from different periods (Mesolithic and late Islamic occupation of Iberia) contained $O$. edulis shells but none which were undoubtedly from Crassostrea sp. (Drago et al., unpublished data).

The presence of $C$. angulata in Europe dates back at least to its description by Lamarck in 1819. C. angulata is of high aquaculture importance, now recognized as one of the most produced species in China (Qin et al. 2012) and sometimes known as the "Fujian oyster". It was the main bivalve species cultured in France until the 1970's when massive mortalities almost led to its disappearance (Comps 1988). Nowadays, the only known sites in NE Atlantic where $C$. angulata is present and $C$. gigas has not been detected at least in large numbers are the Mira and Sado estuaries in Portugal, the Cadiz region in Spain and Tahaddart in Morocco (Fabioux et al. 2002). However, these $C$. angulata beds are threatened by the invasion of C. gigas (Huvet et al. 2000).

Many questions remain unanswered about the introduction of $C$. angulata into Europe and the potential consequences. The objective of the present study was to estimate the genetic diversity and differentiation of $C$. angulata sampled in NE Atlantic and Asian sites. A phylogeographic study was performed using samples collected in Europe, Africa and Asia, and sequence data from a highly polymorphic mitochondrial DNA region.

\section{Material and methods}

\subsection{Sampling sites}

Oysters presumed to be $C$. angulata were sampled from the following sites: Mira estuary in Portugal ( $\left.37^{\circ} 42^{\prime} \mathrm{N}, 8^{\circ} 44^{\prime} \mathrm{W}\right)$ in 2010; Sado estuary in Portugal ( $\left.38^{\circ} 25^{\prime} \mathrm{N}, 8^{\circ} 39^{\prime} \mathrm{W}\right)$ in 2010; Tahaddart bay in Morocco ( $35^{\circ} 35^{\prime} \mathrm{N}, 5^{\circ} 59^{\prime} \mathrm{W}$ ) in 2013; and Nanao island, Shantou, Guangdong province in China $\left(23^{\circ}\right.$ $25^{\prime} \mathrm{N}, 117^{\circ} 04^{\prime} \mathrm{E}$ ) in 2012 . In addition, samples of $C$. angulata collected in Keelung (Taiwan) previously analysed by Boudry et al. (1998) were also studied. A piece of gill tissue ( 2$3 \mathrm{~mm}^{2}$ ) was dissected from each oyster and stored in ethanol (70-95\%). The number of oysters analyzed from each site is given in Table 1.

\subsection{DNA extraction, amplification and sequencing}

DNA was extracted from gill tissue samples using a DNeasy ${ }^{\circledR}$ blood \& tissue kit (QIAGEN) following the manufacturer's instructions. Extracted DNA was then quantified using a spectrophotometer (Nano-Drop Technologies). A 739bp fragment of the major noncoding region (MNR) of mitochondrial DNA was amplified by PCR using the forward (5'-TCACAAGTACATTTGTCTTCCA-3') and reverse (5'AACGTTGTAAGCGTCATGTAAT-3') primers designed by Aranishi and Okimoto (2005). PCR reactions were performed in a final reaction volume of $25 \mu \mathrm{l}$ and contained $2.5 \mu \mathrm{l}$ of $10 \mathrm{X}$ reaction buffer, $16 \mu \mathrm{l}$ of distilled water, $1.5 \mu \mathrm{l}$ of $\mathrm{dNTP}$ (2.5 mM), $1.5 \mu \mathrm{l}$ of $\mathrm{MgCl} 2(25 \mathrm{mM}), 1 \mu \mathrm{l}$ of each primer $(10 \mu \mathrm{M}), 0.5 \mu \mathrm{l}$ of Taq polymerase (Supreme NZYTaq DNA 
polymerase, NZYTECH) and $1.0 \mu \mathrm{l}$ of template DNA (ca. $50 \mathrm{ng}$ ). The amplification cycle consisted of an initial denaturation step at $95^{\circ} \mathrm{C}$ for $5 \mathrm{~min}$, followed by 40 cycles of $20 \mathrm{~s}$ at $95{ }^{\circ} \mathrm{C}, 20 \mathrm{~s}$ at $58{ }^{\circ} \mathrm{C}$, and $1 \mathrm{~min}$ at $72{ }^{\circ} \mathrm{C}$. At the end of these cycles a final extension of $7 \mathrm{~min}$ at $72^{\circ} \mathrm{C}$ was performed. PCR products were purified using NZYgel pure (NZYTECH) following the manufacturer's instructions. Amplicons were separated by electrophoresis on $1.5 \%$ agarose gels, stained with GreenSafe (NZTECH) and visualized under UV light to confirm the expected size and absence of non specific amplification. The purified amplicons were sequenced using the kit ABI PRISM BigDye Terminator v3.1 and an automatic sequencer (Genetic Analyzer 3130xl Applied Biosystems). All singletons were confirmed by repeating the PCR and sequencing analyses.

\subsection{Data analysis}

Chromatograms of the nucleotide sequences were analyzed using Bioedit version 7.0.9.0 (Hall 1999). After editing, multiple sequence alignments were performed using ClustalW (Thompson et al. 1994). Dnasp (version 5.00.03; Rozas et al. 2003) was used to calculate the number of variable sites, number of haplotypes, mean number of nucleotide differences, haplotype diversity and nucleotide diversity. In order to analyze the demographic history of C. angulata, Tajima's D (Tajima 1989), Fu's F (Fu 1997) and $R_{2}$ (Ramos-Onsins and Rozas 2002) were also calculated using Dnasp to test constant population size versus population growth. Negative Tajima's $\mathrm{D}$ and Fu's $\mathrm{F}$ values are expected under a scenario of recent population expansion but can also be a signature of selection (non-neutral evolution). Low $\mathrm{R}_{2}$ values are expected after a recent severe population growth event (Ramos-Onsins and Rozas 2002). The statistical significance of Tajima's D, Fu's $\mathrm{F}$ and $\mathrm{R}_{2}$ values was calculated with coalescence simulations implemented in Dnasp. ARLEQUIN (version 3.11) was used to calculate pairwise genetic differentiation (Fst) using 1000 permutations (Excoffier et al. 2005). A median joining network (Bandelt et al. 1999) was constructed using PopArt (version 1.7; http://popart.otago.ac.nz).

\section{Results}

A total of 60 haplotypes were identified comparing 130 individual nucleotide sequences (length 656-658 bp) of the major noncoding region (MNR) fragment of the mitochondrial genome of $C$. angulata (Genbank accession numbers KY217737-KY217796). The number of total variable sites was 64 and the mean number of nucleotide differences was 5.07. Five indels were observed and the other mutations detected were 59 transitions and 5 transversions.

All haplotypes (with the exception of two sequences from Tahaddart) shared high nucleotide sequence similarity (>98\%) for the corresponding region of $C$. angulata mitochondrial genomes (Ren et al. 2010, 2016). Some haplotypes observed in the present study (H5, H6, H11, H32 and H33) were identical to the respective region of the $C$. angulata mitochondrial genomes (Genbank accession numbers KJ855246, KJ855247,

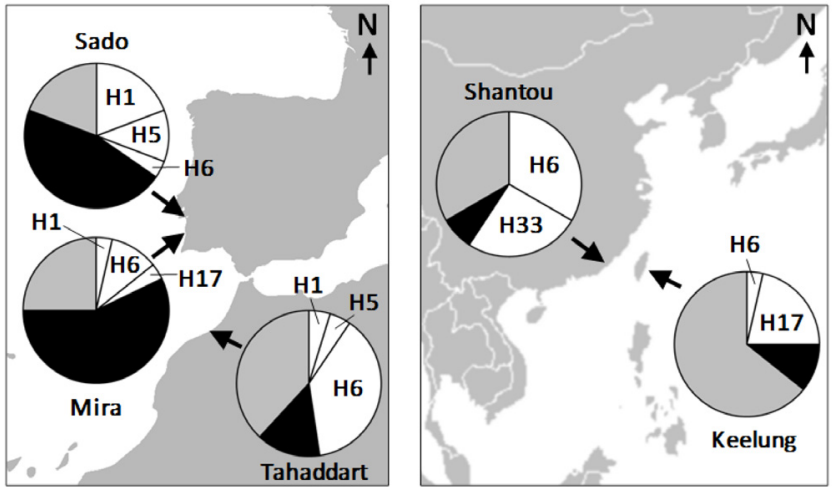

Fig. 1. Haplotype frequencies of $C$. angulata collected in Portugal (Mira and Sado estuaries), Morocco (Tahaddart), Taiwan (Keelung) and China (Shantou). The pie charts show the frequency of the main haplotypes (H1, H5, H6, H17 and H33), unique haplotypes (in gray) and haplotypes shared with other locations (in black).

KJ855248, KJ855249 and EU672832) (Ren et al. 2016). Only two haplotypes, detected in Tahaddart, showed a high nucleotide identity (99.8 and $100 \%)$ with haplotypes previously described for C. gigas (KJ855243; Ren et al. 2006); they were excluded from the analysis. The nucleotide divergence among $C$. angulata MNR haplotypes ranged from 0.2 to $1.9 \%$. The nucleotide divergence between $C$. angulata and $C$. gigas MNR haplotypes (haplotypes identified by Moehler et al. 2011 with the accession numbers JF505202-JF505277 and position 10615 to 11253 bp of EU672831) ranged from 8.2 to $10.2 \%$.

Table 1 shows the number of $C$. angulata haplotypes detected at each site. The Sado and Mira sites shared seven haplotypes, which was the highest number of shared haplotypes. Haplotype H6 was common to all sites and had the highest overall frequency (16.9\%). It was the most frequent haplotype observed in the Shantou site (33\%, Fig. 1). The analysis of a Median-joining network constructed using all the haplotypes identified in the study showed that haplotype H6 had a central position and hence is likely to be an ancestral haplotype (Fig. 2). Ten out of 11 haplotypes observed in the Shantou site were only observed in this site (i.e. private haplotypes). Among the 60 haplotypes detected, only four were shared between the NE Altantic sites (Mira, Sado and Tahaddart) and Asian sites (Shantou and Keelung).

The frequency of unique haplotypes observed in each site ranged from 19.2 to $64.3 \%$. Haplotype diversity ranged from 0.832 to 0.960 and nucleotide diversity from 0.00594 to 0.00791 (Table 1). Significant pairwise genetic differentiation (Fst estimates between 0.102 and 0.228 ) after Bonferroni correction was observed between all NE Atlantic sites and the two Asian sites (Table 2). However, no significant Fst estimates (0.003 - 0.072) were observed among the NE Atlantic sites. A significant Fst value of 0.151 was estimated between Shantou and Keelung (Table 2). Significant negative Tajima's D values were observed in Shantou and Keelung sites (Table 3) and significant Fu's F negative values were observed in Mira and Keelung sites. Moreover, significant $\mathrm{R}_{2}$ values were observed in all sites (Table 3). 


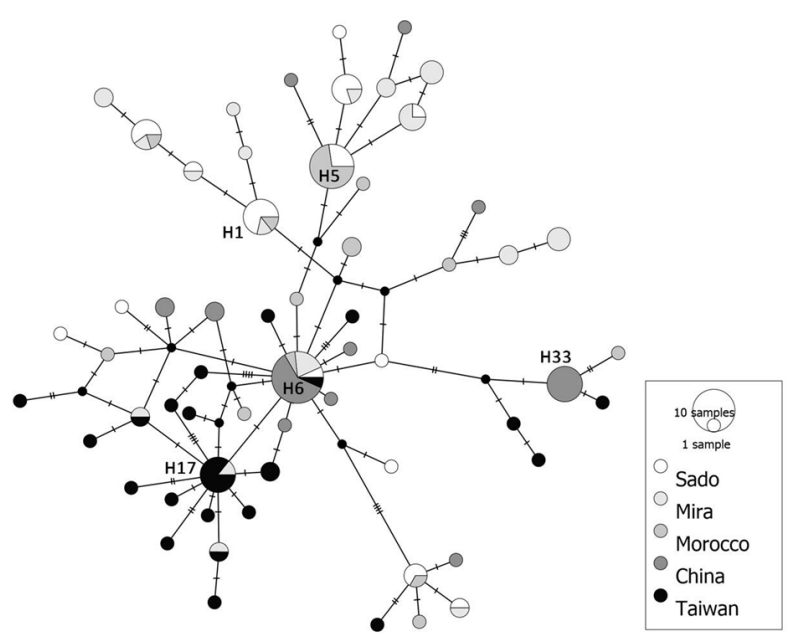

Fig. 2. Median joining network of $C$. angulata DNA haplotypes of a fragment (position 10617-11217 bp of EU672832) of the major noncoding region of the mitochondrial genome. The size of circles corresponds to haplotype frequency and the different colours represent the geographical sites where the haplotypes were observed. The number of perpendicular bars on branches represents the number of mutational steps (indels and/or substitutions) between haplotypes.

Table 2. Pairwise genetic differentiation (Fst) for $C$. angulata samples collected in North East Atlantic and Asia.

\begin{tabular}{cccccc}
\hline & 1 & 2 & 3 & 4 & 5 \\
\hline 1. Sado (Portugal) & - & & & & \\
\hline 2. Mira (Portugal) & 0.0641 & - & & & \\
3. Tahaddart (Morocco) & 0.0029 & 0.0717 & - & & \\
4. Shantou (China) & $\mathbf{0 . 1 2 4 4}$ & $\mathbf{0 . 1 6 0 0}$ & $\mathbf{0 . 1 0 1 8}$ & - & \\
5. Keelung (Taiwan) & $\mathbf{0 . 2 2 5 0}$ & $\mathbf{0 . 1 4 1 8}$ & $\mathbf{0 . 2 2 8 2}$ & $\mathbf{0 . 1 5 0 8}$ & - \\
\hline
\end{tabular}

Values in bold are significant after Bonferroni correction $(p<0.05)$.

\section{Discussion}

The analysis of the nucleotide sequence of a highly polymorphic non-coding mitochondrial region of $C$. angulata samples collected in Europe, Africa and Asia provided new insight into the introduction of this taxon from Asia into the NE Atlantic region. We observed high genetic diversity in $C$. angulata from the NE Atlantic region and genetic differentiation between three NE Atlantic and two Asian sites. Recently, Ren et al. (2016) analyzing intraspecific variation in mitogenomes of $C$. gigas, $C$. angulata, $C$. sikamea, $C$. ariakensis and $C$. hongkongensis observed an overall between species nucleotide diversity ranging from 0.00106 to 0.00683 . Using this data, we calculated a nucleotide diversity of 0.0085 from five $C$. ang $u$ lata mitogenomes (one of the individuals was collected in Portugal and the other four in China; KJ855246-KJ855249 and EU672832) published by Ren et al. (2016) for the mitochondrial region that we studied (i.e. MNR). We obtained a similar nucleotide diversity of 0.0077 for $C$. angulata from the present dataset. Repeating the analysis for the MNR fragments from five $C$. gigas mitogenomes (KJ855241-KJ855245, Ren et al. 2016) resulted in a nucleotide diversity of 0.0049 , which was higher than the overall nucleotide diversity of 0.0019 obtained for $C$. gigas by Ren et al. (2016). This difference between
Table 3. Neutrality and demographic tests for C. angulata samples estimated from sequences of the major noncoding region (position 10617-11217 bp of EU672832) of mitochondrial DNA.

\begin{tabular}{ccccc}
\hline Site & $n$ & Tajima's D & Fu's F & $\mathrm{R}_{2}$ \\
\hline Sado (Portugal) & 26 & -0.4204 & -3.104 & $\mathbf{0 . 1 0 5 5}$ \\
\hline Mira (Portugal) & 28 & -0.2869 & -5.767 & 0.1143 \\
Tahaddart (Morocco) & 21 & -1.1681 & -3.833 & $\mathbf{0 . 0 8 4 8}$ \\
Shantou (China) & 27 & $\mathbf{- 1 . 6 2 1 4}$ & -1.541 & $\mathbf{0 . 0 7 0 3}$ \\
Keelung (Taiwan) & 28 & $\mathbf{- 2 . 1 7 0 8}$ & $\mathbf{- 1 8 . 0 5 3}$ & $\mathbf{0 . 0 4 4 8}$ \\
\hline
\end{tabular}

$\mathrm{R}_{2}$, Ramos-Onsins and Rozas statistic. Values in bold are significantly different $(p<0.05)$.

the overall mitochondrial genome and MNR region confirms that the mitochondrial region analyzed in the present study is indeed a highly polymorphic region, as was previously suggested by Aranishi and Okimoto (2005) for C. gigas.

The nucleotide diversity of $C$. angulata observed in the present study was higher than that previously reported for $C$. gigas for the same mitochondrial region. Moehler et al. (2011) and Lallias et al. (2015) reported nucleotide diversity values of 0.0044 and 0.0046 for $C$. gigas, respectively, with samples mainly collected in Europe but also in Canada and Japan. Hsiao et al. (2016) found haplotype and nucleotide diversities (using mitochondrial cytochrome oxidase I sequences) in Asia being considerably higher in $C$. angulata than in $C$. gigas. This suggests that the number of $C$. angulata individuals introduced into the NE Atlantic must have been sufficiently high to reflect the genetic diversity of $C$. angulata in its native range. In addition to the number of individuals introduced, other factors may influence the genetic diversity of introduced species such as the number of introduction events. It is possible that $C$. angulata was introduced via multiple introduction events and that this may explain the high nucleotide diversity observed in the NE Atlantic relative to the Asian sites. Other possible explanations are that the origin of $C$. angulata was not the two Asian sites analyzed in the present study (i.e. Keelung and Shantou) or that haplotype diversity strongly changed in these sites since the introduction of $C$. angulata into Europe. Indeed, only four out of 60 haplotypes were shared between the NE Atlantic and the two Asian sites. Moreover, the significant Fst values observed between the NE Atlantic sites and the Keelung and Shantou sites support the hypothesis that these two sites were not the source of the introduction. Huvet et al. (2000) using microsatellite loci also observed a significant Fst value of 0.0173 between Mira and Keelung sites. Our results therefore do not support the hypothesis that $C$. angulata might have been introduced from Taiwan (for which $C$. angulata DNA-based identification was first reported) to Portugal. The hypothesis is based on previous studies using PCR-RFLP haplotypes of a fragment of the mitochondrial gene cytochrome oxidase subunit I (COI) (Boudry et al. 1998; Huvet et al. 2000). An explanation of this result comes from the much higher polymorphism of MNR sequence data in comparison with RFLP-based COI. Since $C$. angulata is known to be widespread along the southern coast of China (Wang et al. 2010) it is likely that there are other areas that could have been the origin of the NE Atlantic $C$. angulata populations. Consequently, further analyses of $C$. angulata populations in Asia are needed to trace the 
putative source(s) of this introduction. However, it cannot be ruled out that the source of $C$. angulata in Asia may have been lost due to anthropogenic activities (seed exchange in relation with aquaculture production) or natural causes (e.g. disease outbreaks), which would then make the NE Atlantic $C$. angulata resources unique.

The lack of genetic differentiation of $C$. angulata from the Sado, Mira and Tahaddart is in agreement with the hypothesis that $C$. angulata was mainly introduced to a single location in Europe (probably the Tagus River, which was one of the main ports for anchoring ships from Asia), from where it was introduced to other locations in the NE Atlantic. For example, it is documented that $C$. angulata was introduced into Morocco from Spain and Portugal in 1952 (Shafee 1985 cited in Fabioux et al. 2002). In contrast to C. gigas in Europe, which showed a typical star-shaped haplotype phylodiversity characteristic of expanding populations (Moehler et al. 2011; Lallias et al. 2015), the haplotype network of $C$. angulata did not show such a pronounced star-shape. Significant negative Tajima's D values were only found for $C$. angulata samples from Asia, although Fu's $F$ tests were significant for Mira and Keelung samples. Significant $R_{2}$ values were observed for all sites. For small samples the $\mathrm{R}_{2}$ test is more powerful than Tajima's D and Fu's F tests for detecting population growth (Ramos-Onsins and Rozas 2002). Thus, our results suggested that a demographic expansion event occurred recently in C. angulata. This is in agreement with the results of Hsiao et al. (2016) who suggested that $C$. angulata in Asia experienced a sudden population expansion after the last glacial maxima. However, the results from Tajima's $D$, Fu's $F$ and $R_{2}$ tests obtained in the present study and in other studies have to be considered cautiously since the coalescent model used may be inappropriate for highly fecund species such as $C$. angulata (Steinrucken et al. 2013).

\section{Conclusions}

We observed higher nucleotide diversity for $C$. angulata in NE Atlantic sites than in the studied Asian sites. Moreover, significant genetic differentiation was detected between $C$. angulata from three NE Atlantic and two Asian sites. Our results suggested that $C$. angulata might have been introduced into the NE Atlantic through multiple introductory events. However, further analyses in Asia are needed to identify the source(s) of the introduction(s) since none of the Asian sites studied seemed to have been the origin. The NE Atlantic $C$. angulata stocks appear to be unique genetic resources, which highlights the importance of their conservation.

Acknowledgements. This work was funded by the Marinaqua project (03-01-FPE-0013), the European Union Atlantic Area Transnational Programme (2007-2013) project SEAFARE (Grant agreement No. 2009-1/123) and the ShareBiotech consortium within the ShareBiotech project co-financed with the support of the ERDF-Atlantic Area programme (priority 1 INTERREG IVB). However, it does not reflect the European Union's, INTERREG IV B Atlantic Area programmes or local Governments views and in no way anticipates their future policy in this area. F.M. Batista was funded by FCT
(SFRH/BPD/108591/2015). We would like to thanks Professor Ziniu Yu for providing samples from Shantou (China). We also would like to thank two anonymous reviewers for their constructive and helpful comments.

\section{References}

Aranishi F., Okimoto T., 2005, Sequence polymorphism in a novel noncoding region of Pacific oyster mitochondrial DNA. J. Appl. Genet. 46, 201-206.

Bandelt H., Forster P., Röhl A., 1999, Median-joining networks for inferring intraspecific phylogenies. Mol. Biol. Evol. 16, 37-48.

Batista F.M., Leitão A., Fonseca V. G., Ben-Hamadou R., Ruano F., Henriques M.A., Guedes-Pinto H., Boudry P., 2007, Individual relationship between aneuploidy of gill cells and growth rate in the cupped oysters Crassostrea angulata, C. gigas and their reciprocal hybrids. J. Exp. Mar. Biol. Ecol. 352, 226-233.

Batista F.M., Leitão A., Huvet A., Lapègue S., Heurtebise S., Boudry P., 2009, The taxonomic status and origin of the Portuguese oyster Crassostrea angulata (Lamark, 1819). Special Edition of the Proceedings of the 1st \& 2nd International Oyster Symposiums 24, pp. 5-13.

Boudry P., Heurtebise S., Collet B., Cornette F., Gérard. A., 1998, Differentiation between populations of the Portuguese oyster, Crassostrea angulata (Lamark) and the Pacific oyster, Crassostrea gigas (Thunberg) revealed by mtDNA RFLP analysis. J. Exp. Mar. Biol. Ecol. 226, 279-291.

Boxer C.R., 1969, The Portuguese seaborne empire, 1415-1825, [1st American ed.], A.A. Knopf, New York, p. 426.

Buroker N.E., Hershberger W.K., Chew K.K., 1979, Population genetics of the family Ostreidae. I. Intraspecific studies of Crassostrea gigas and Saccostrea commercialis. Mar. Biol. 54, 157-169.

Comps M., 1988, Epizootic diseases of oysters associated with viral infections. In: Fisher, W.S. (Ed.), Disease processes in marine bivalve molluscs. American Fisheries Society Special Publication Bethesda, MD 8, pp. 23-37.

Cross I., Rebordinos L., Diaz E., 2006, Species identification of Crassostrea and Ostrea oysters by polymerase chain reaction amplification of the 5S rRNA gene. J. AOAC Int. 89, 144-148.

EFSA, 2010, EFSA Panel on Animal Health and Welfare (AHAW); scientific opinion on the increased mortality events in Pacific oyster (Crassostrea gigas). EFSA J. 8, 1894.

Excoffier L., Laval G., Schneider S., 2005, Arlequin (version 3.0): an integrated software package for population genetics data analysis. Evol. Bioinform. 1, 47-50.

Hsiao S.-T., Chuang S.-C., Chen K.-S., Ho P.-H., Wu C.-L., Chen C.A., 2016, DNA barcoding reveals that the common cupped oyster in Taiwan is the Portuguese oyster Crassostrea angulata (Ostreoida; Ostreidae), not C. gigas. Scientific Reports 6: 34057.

Fabioux C., Huvet A., Lapègue S., Heurtebise S., Boudry P., 2002, Past and present geographical distribution of populations of Portuguese (Crassostrea angulata) and Pacific (C. gigas) oysters along the European and north African Atlantic coasts. Haliotis 31, 33-44.

Fu Y.X., 1997, Statistical tests of neutrality of mutations against population growth, hitchhiking and background selection. Genetics 147, 915-925.

Gutiérrez-Zugasti I., Andersen S. H., Araújo A.C., Dupont C., Milner N., Monge-Soares A.M., 2011, Shell midden research in Atlantic Europe: State of the art, research problems and perspectives for the future. Quaternary International 239, 70e85. 
Hall T.A., 1999, BioEdit: a user-friendly biological sequence alignment editor and analysis program for Windows 95/98/NT. Nucleic Acids Symp. Ser. 41, 95-98.

Huvet A., Lapègue S., Magoulas A., Boudry P., 2000, Mitochondrial and nuclear DNA phylogeography of Crassostrea angulata, the Portuguese oyster endangered in Europe. Conserv. Gen. 1, 251262.

Huvet A., Gérard A., Ledu C., Phélipot P., Heurtebise S., Boudry P., 2002, Is fertility of hybrids enough to conclude that the oysters Crassostrea gigas and Crassostrea angulata are the same species? Aquat. Living Resour. 15, 45-52.

Huvet A., Fabioux C., McCombie H., Lapègue S., Boudry P., 2004, Natural hybridization between genetically differential populations of Crassostrea gigas and $C$. angulata highlighted by sequence variation in flanking regions of a microsatellite locus. Mar. Ecol. Prog. Ser. 272, 141-152.

Imai T., Sakai S., 1961, Study of breeding of Japanese oyster, Crassostrea gigas. Tohoku J. Agric. Res. 12, 125-171.

Lallias D., Boudry P., Batista F.M., Beaumont A., King J.W., Turner J.R., Lapègue S., 2015, Invasion genetics of the Pacific oyster Crassostrea gigas in the British Isles inferred from microsatellite and mitochondrial markers. Biol. Invasions 17, 2581-2595.

Lapègue S., Batista F.M., Heurtebise S., Yu Z., Boudry P., 2004, Evidence for the presence of the Portuguese oyster, Crassostrea angulata, in Northern China. J. Shellfish Res. 23, 759-763.

López-Flores I., Hérran R., Garrido-Ramos M.A., Boudry P., RuizRejón C., Ruiz-Rejón M., 2004, The molecular phylogeny of oysters based on a satellite DNA related to transposons. Gene 339, 181-188.

Mathers, N.F., Wilkins N.P., Walne P.R., 1974, Phosphoglucose isomerase and esterase phenotypes in Crassostrea angulata and $C$. gigas. Biochem. System. Ecol. 2, 93-96.

Menzel R.W., 1974, Portuguese and Japanese oysters are the same species. J. Fisheries Res. Board Canada 31, 453-456.

Moehler J., Wegner K.M., Reise K., Jacobsen S., 2011, Invasion genetics of Pacific oyster Crassostrea gigas shaped by aquaculture stocking practices. J. Sea Res. 66, 256-262.

O'Foighil D., Gaffney P.M., Wilbur A.E., Hilbish T.J., 1998, Mitochondrial cytochrome oxidase I gene sequences support an Asian origin for the Portuguese oyster Crassostrea angulata. Mar. Biol. 131, 497-503.

Qin J., Huang Z., Chen J., Zou Q., You W., Ke C., 2012, Sequencing and de novo analysis of Crassostrea angulata (Fujian Oyster) from 8 different developing phases using 454 GSFlx. PLoS One 7, e43653.
Ramos-Onsins S.E., Rozas J., 2002, Statistical properties of new neutrality tests against population growth. Mol. Biol. Evol. 19, 20922100.

Ranson G., 1960, Les prodissoconques (coquilles larvaires) des ostréides vivants. Bull. Inst. Océanogr. Monaco 1, 1-41.

Ren J., Liu X., Jiang F., Guo X., Liu B., 2010, Unusual conservation of mitochondrial gene order in Crassostrea oysters: evidence for recent speciation in Asia. BMC Evol. Biol. 10, 394.

Ren J., Hou Z., Wang H., Sun M.A., Liu X., Liu B., Guo, X., 2016, Intraspecific variation in mitogenomes of five Crassostrea species provides insight into oyster diversification and speciation. Mar. Biotechnol. 18, 242-254.

Rozas J., Sanchez-DelBarrio J.C., Messeguer X., Rozas R., 2003, DnaSP, DNA polymorphism analyses by the coalescent and other methods. Bioinformatics 19, 2496-2497.

Seebens H., Gastner M., Blasius B., 2013, The risk of marine bioinvasion caused by global shipping. Ecology Letters 16(6), 782-790.

Sekino M., Yamashita H., 2013, Mitochondrial DNA barcoding for Okinawan oysters: a cryptic population of the Portuguese oyster Crassostrea angulata in Japanese waters. Fish. Sci. 79, 61-76.

Simberloff D., Martin J.-L., Genovesi P., Maris V., Wardle D.A., Aronson J., Courchamp F., Galil B., García-Berthou E., Pascal M., Pyšek P., Sousa R., Tabacchi E., Vila M., 2013, Impacts of biological invasions: what's what and the way forward. Trends Ecol. Evol. 28, 58-66.

Steinrücken M., Birkner M., Blath J., 2013, Analysis of DNA sequence variation within marine species using Beta-coalescents. Theor. Popul. Biol. 87, 15-2-4.

Tajima F., 1989, Statistical method for testing the neutral mutation hypothesis by DNA polymorphism. Genetics $123,585-595$.

Thompson J.D., Higgins D.G., Gibson T.J., 1994, CLUSTALW: improving the sensitivity of progressive multiple sequence alignment through sequence weighting, position specific gap penalties and weight matrix choice. Nucleic Acids Res. 22, 4673-4680.

Wang H., Qian L., Liu X., Zhang G., Guo X., 2010, Classification of a common cupped oyster from southern China. J. Shellfish Res. $29,857-866$.

Xia J., Yu Z., Kong X., 2009, Identification of seven Crassostrea oysters from the South China Sea using PCR-RFLP analysis. J. Mollusc. Stud. 75, 139-146. 